\title{
Composição Dramatúrgica: Práticas de criação cênica
}

\author{
Patrícia Fagundes \\ Universidade Federal do Rio Grande do Sul - UFRGS, Porto Alegre, Brasil \\ E-mail: patfag26@hotmail.com
}

Resumo

O trabalho reflete sobre conceitos e práticas de dramaturgia desenvolvidas durante o processo de ensaios, em montagens em que cena e texto são criados de modo simultâneo e interligado, a partir da perspectiva do teatro como arte corpórea, relacional e efêmera. Apresenta-se a noção de composição dramatúrgica, prática de escrita cênica que promove autorias compartilhadas, mediante procedimentos heterogêneos em que movimento, palavra, corpo, política e est(é)tica dialogam na experiência de fazer teatro no século XXI no sul do Brasil, inventando as próprias narrativas.

Palavras-chave

Dramaturgia. Processo de Ensaios.

Encenação. Festividade. Teatro.
Abstract

The work reflects on concepts and practices of dramaturgy devised during the rehearsal process, in productions where staging and text are created in simultaneous and interconnected ways, from the perspective of theater as a corporeal, relational and ephemeral art. In this context, we introduce the notion of dramaturgic composition, a practice of scenic writing that promotes shared authorship, through heterogeneous procedures, where movement, word, body, politics, ethics and esth(e)tics dialogues in the experience of doing theater in the 21st century in the south of Brazil, inventing our own narratives.

Dramaturgy. Rehearsal Process.

Directing. Festivity. Theater. 
No momento histórico em que vivemos, a disputa de narrativas evidencia-se como questão decisiva na arena social, econômica e política do país e do mundo. A percepção da realidade como uma construção social e sua frequente elaboração como narrativa que serve a objetivos de determinadas estruturas de poder acentuam a urgência de articular outras possibilidades. Que histórias queremos contar? Como podemos narrar nosso tempo, nosso passado e nossos desejos de futuro? Neste contexto, a arte pode oferecer recursos importantes por meio de seu múltiplo fazer narrativo, que inventa, compõe, desvenda, contrapõe, revela. Katia Canton denomina as formas contemporâneas não lineares de contar histórias com o termo narrativas enviesadas, que, perante o excesso de imagens e informações aceleradas que varrem o mundo, valorizam o encontro e a prática de contar histórias, que "se transforma em um jeito de se aproximar do outro e, na troca entre ambos, de gerar sentido em si e nesse outro" (CANTON, 2009, p. 37).O teatro, arte que se faz no encontro de pessoas em um mesmo espaço/tempo compartilhado, oferece especial contexto, tradições e práticas para desenvolver nossas histórias, outras histórias, distintas das narrativas oficiais do poder, como aponta o artista Eugenio Lima:

Existem diversos grupos fazendo diversas coisas profundamente organizadas, potentes, poéticas e o Legítima Defesa é uma delas dentro desse processo histórico em curso-que não começou e com certeza não vai terminar com a gente. Nós estabelecemos um diálogo a partir da ideia de que é necessário descolonizar esse fazer teatral. (...)... criar uma outra possibilidade de organizar a narrativa. Porque o que a gente quer disputar é a narrativa, é quem conta a história, como conta a história e quais são as formas que eu utilizo pra contar essa história (LIMA, 2007, n.p.).
Considerando o desafio, a pluralidade e a importância desse fazer de diversos grupos contando suas histórias, este trabalho busca refletir sobre procedimentos e práticas de criação dramatúrgica durante o processo de ensaios e compartilhá-los, no intuito de contribuir na formação de repertório em um campo fundamental do fazer teatral, a partir da experiência concreta da criação. Essa reflexão não pretende tecer um panorama histórico nem mapear todas as práticas possíveis de criação de dramaturgia durante o processo de ensaios. Articula-se a partir de um recorte específico: a experiência criativa da autora em diversas montagens desenvolvidas entre 2010 e 2018 junto à Cia. Rústica de Teatro ${ }^{1}$, núcleo de criação cênica sediado em Porto Alegre (RS). Neste campo concreto de experiências, a encenação e a dramaturgia entretecem-se no próprio corpo da artista, que assume a função de diretora-dramaturga, propondo e agenciando contribuições de toda a equipe.

Assim, no exercício de uma prática teorizada (CAUQUELIN, 2005), que se constrói a partir do ponto de vista do artista na experiência viva da criação, propõe-se a noção de composição dramatúrgica para referir-se a essa dramaturgia textual desenvolvida durante o período de ensaios, que incorpora materiais de diversas fontes e envolve o corpo e suor de um trabalho cênico desenvolvido em colaboração. O termo não implica uma prática exclusiva ou inovadora, mas um recorte, um modo de fazer que dialoga com outros modos contemporâneos de produção.

A recorrente criação de dramaturgia em processo desenvolve-se de formas diversas em cada experiência, contexto, equipe de trabalho ou proposta de encenação. $\mathrm{Na}$ Inglaterra, o termo devising theatre define toda uma linha de criação teatral na qual o

1 Fundada em 2004, como uma "zona autônoma de trabalho entre artistas plurais". Ver www.ciarustica.com ou https://www. facebook.com/ciarusticadeteatro/ou Instagram @ciarústica . 
texto dramático não é ponto de partida ou protagonista entre os elementos cênicos, e a dramaturgia é desenvolvida colaborativamente durante o período de ensaios. Em seu estudo sobre devising theatre e práticas contemporâneas de inventar histórias (devising histories), as artistas e professoras Emma Govan, Helen Niccholson e Katie Normington (University of London) afirmam:

\begin{abstract}
A tradição inventada da devised performance não apresenta, obviamente, uma única estética ou objetivo ideológico; suas estratégias e métodos partem de um amplo espectro de campos culturais, incluindo teatro político e comunitário, teatro físico, artes vivas e da performance. (...) A devised performance é estreitamente conectada ao contexto e momento da produção, e novas práticas foram inventadas para ampliar noções do que a cena pode ser. Devising oferece, assim, a flexibilidade para habilitar criadores teatrais a abordar problemáticas e interrogar questões pessoais. (...) Devised theatre ou 'devised performance' é algumas vezes usada como substantivo para indicar uma obra original desenvolvida por uma companhia ou algumas vezes artistas solo, mas seria equivocado sugerir que este termo guarda-chuva significa um gênero dramático ou estilo de performance específico ${ }^{2}$. (GOVAN, NICCHOLSON, NORMINGTON, 2007, p. 4).
\end{abstract}

O conceito de composição dramatúrgica relaciona-se a alguns dos elementos citados pelas autoras, como a relação direta

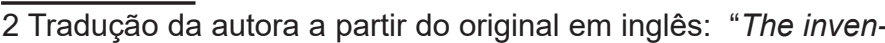
ted tradition of devised performance has, of course, no single aesthetic or ideological objective; its strategies and methods are indebted to a wide range of cultural fields including political and community theatres, physical theatre, performance and live art. (...) Devised performance is closely connected to the context and moment of the production, and new practices have been invented to extend notions of what performance may be. Devising has, therefore, the flexibility to enable theatre makers to address matters of personal concern, to interrogate personal issues (...) 'Devised theatre or 'devised performance' is sometimes used as a noun do indicate that is an original piece of work developed by a company or sometimes by solo performers, but would be misleading to suggest this umbrella term signifies any particular dramatic genre or a specific style of performance".
}

com um contexto específico, a possibilidade de desenvolver material biográfico e temáticas emergentes, a criação autoral de uma peça e a "prática de gerar, modelar e editar novo material em uma montagem original"3 (2007, p. 6). Na noção proposta neste trabalho, o procedimento da escrita situa-se em um campo diferente da autoria individualizada desenvolvida previamente aos ensaios e também de dramaturgias coletivas, assinadas indistintamente por toda a equipe, ou seja: um artista (no campo de experiências considerado, a encenadora) assume a função da composição dramatúrgica, ainda que textos de diversas fontes possam ser incorporados à estrutura textual. A criação dá-se em dinâmicas que articulam uma forte sinergia entre encenação, atuação e dramaturgia, tecidas em uma trama indissociável. Consideramos que tal sinergia não é uma exclusividade da cena contemporânea, remetendo a práticas históricas do teatro, como o período elisabetano - em seu tempo, Shakespeare era um criador e produtor que escrevia textos teatrais junto à cena, a partir do material humano disponível em sua companhia, incorporando referências, estruturas e fragmentos de diversas fontes. Por outro lado, sem deixar de dialogar com tradições do fazer teatral, a composição dramatúrgica afirma sua independência de parâmetros literários do gênero dramático, que não guiam necessariamente o processo criativo.

Ao pensar em um fazer dramatúrgico teatral, a expansão e diversidade das noções e práticas cênicas contemporâneas levam-nos à necessidade de definir o próprio conceito de "teatro", suscetível a diferenças. No âmbito deste trabalho, compreende-se teatro como um fenômeno que acontece em um espaço-tempo compartilhado entre

3 Tradução da autora a partir do original em inglês: "The practice
of generating, shaping and editing new material into an original
performance remains a central dynamic of devised performance". 
pessoas, que depende da presença física no aqui-e-agora, uma arte processual, corpórea e lúdica. Em sua teorização sobre a cena contemporânea, Lehmann valoriza esse aspecto relacional em sua definição:

\begin{abstract}
O teatro não é apenas o lugar dos corpos submetidos à lei da gravidade, mas também o contexto real em que ocorre um entrecruzamento único de vida real cotidiana e de vida esteticamente organizada. (...) teatro significa "um tempo de vida em comum" em que atores e espectadores passam juntos no ar que respiram juntos daquele espaço em que a peça teatral e os espectadores se encontram frente a frente. (LEHMANN, 2007, p. 18).
\end{abstract}

No entendimento e prática do teatro como arte corpórea, relacional e efêmera, que acontece no encontro e confronto de presenças, não apenas no momento de apresentação pública, mas também em seus processos criativos, fundamenta-se a noção de composição dramatúrgica. Uma escrita plural, profundamente conectada à cena viva, atravessada por múltiplas contribuições em que narrativas não lineares são geradas mediante processos próprios das artes cênicas.

Afastar-se da literatura dramática como modelo não implica sua recusa, já que a "arte simplesmente não pode se desenvolver sem estabelecer relações com formas anteriores" (LEHMANN, 2007, p. 34). Um dos princípios dessa noção de composição é justamente a bricolagem, a mistura de diversos referenciais que operam na geração de outra estrutura. Somos nossas vivências e referências, canibalizamos e reinventamos perspectivas e procedimentos evidenciados no campo da arte em tempos de reciclagem, remixagem, sample, releituras. A bricolagem assume a possibilidade de incorporar elementos diversos, fragmentos de textos de diferentes origens e formatos, desenvolver polifonias, apropriações e reinvenções; aproximando-se também das nar- rativas enviesadas propostas por Canton.

A palavra e seus sentidos, a herança e a
tradição são elementos que passam a ser
revalorizados num mundo inundado por
imagens fosforescentes, propagadas in-
cessantemente pela mídia. Eles formam
uma narrativa que incorpora sobreposi-
ções, fragmentações, repetições, simulta-
neidade de tempo e espaço - enfim, todo
o jogo que pode fornecer elementos para
a criação de uma obra de sentido aberto,
que se constrói durante a relação com o
outro, com o público, com o leitor, com
o observador. (CANTON, 2009, p. 37 ).

Ou seja, histórias "que narram, porém não necessariamente resolvem as próprias tramas" (CANTON, p. 15). No campo de experiências cênicas considerado, a palavra constitui um importante elemento, em modo de poesia, prosa, canção, manifesto, diálogo, narração, projeção, áudio, poéticas vocalizadas, palavra encarnada que "lembra, anuncia e transmite; ela nos atravessa e passa por nós sem que se saiba. As palavras não são objetos manipuláveis" (NOVARINA, 2009, p. 16). Em tempos de supremacia da imagem, Novarina afirma que a poesia nunca foi tão política.

As montagens ${ }^{4}$ que se oferecem como campo de investigação, laboratório de pesquisa e rede de referência para esta reflexão assumem modelos cênicos diversos, mais ou menos abertos, ocupando tanto a rua quanto salas fechadas, com equipes mais ou menos numerosas (de solos a espetáculos com 12 atores e atrizes). Como traço comum, nasceram de projetos sem texto prévio completamente definido, que foi gerado por meio de processos heterogêneos, guiado pelos desejos e planos do projeto inicial. Outro traço comum é o diálogo com a noção de

\footnotetext{
4 Clube do Fracasso (2010), O Fantástico Circo-Teatro de um Homem Só (2011), Natalício Cavalo e Cidade Proibida (2013), Cabarés da Rústica (2016 e 2017), Fala do Silêncio (2017), Desmedida Naichty Club e Boca no Mundo (2018). Ver www.ciarustica.com, que dá acesso a links específicos para cada montagem.
} 
festividade na criação cênica ${ }^{5}$, referente a um entendimento do teatro e de seus processos como microterritórios de sociabilidade que forjam seus próprios modos de sensibilidade e convívio, com o potencial de articular uma ética que celebra o prazer na relação com o mundo e com o outro, a possibilidade de dançar no caos, reconhecendo a dolorosa dificuldade de conviver com o outro, de negociar com a diferença. Entende-se o prazer como um vetor de desobediência que cria linhas de fuga; a festa, como uma forma de negociar com a morte e reinventar o mundo.

A seguir, apresenta-se um esquema que organiza princípios e práticas de criação dramatúrgica articuladas em diferentes montagens, as quais serão eventualmente citadas como exemplos (sem o intuito de uma análise detalhada de cada processo e modelo narrativo, o que fugiria ao escopo deste artigo). Trata-se de um conjunto de reflexões e procedimentos para o desenvolvimento de uma dramaturgia entretecida com a cena, em dinâmicas atravessadas por contribuições e contaminações múltiplas: dos artistas envolvidos, do corpo em movimento, do tempo-espaço, do contexto histórico-social vivido, dos encontros e fricções entre todos. As condições e operações dessa prática podem ser divididas em alguns campos que operam em simultaneidade, de forma não linear, em diálogo e ciclos contínuos: plataformas, matérias, disparadores e montagem.

PLATAFORMAS PARA CRIAÇÃO: possíveis pontos de partida para o desenvolvimento do processo que podem oferecer uma base para a aventura movediça da criação de dramaturgia durante os ensaios.

Estrutura central ou frame: referência básica estrutural, espécie de armação a ser desenvolvida, inspirada em modelos narra- tivos existentes em nosso repertório cultural. Pode ser identificada em espetáculos estruturados como conferência, show televisivo, exposição de artes visuais, carnaval, circo, desfile, cabaré artístico, etc. Constitui modelos episódicos e abertos, permitindo a incorporação de diversos elementos textuais e cênicos, que não dependem de uma evolução linear. A estrutura pode ser entendida como uma tela que oferece espaços para múltiplas composições, uma inspiração para o roteiro. Não se apresenta como um modelo rígido, tampouco determina um estilo específico. A referência do circo, por exemplo, pode operar como estrutura agregadora de números mais ou menos independentes, inspiração para tipos icônicos, como trapezista ou mágico, mas não determina temática, gênero, proposta de encenação ou atuação, etc.; pode gerar um circo de horrores, um espetáculo para crianças, uma sátira política ou uma comédia poética, entre tantas possibilidades. Diferentes modelos de estrutura podem ser combinados em uma mesma montagem: uma cena com referência de telejornal, outra de baile de debutantes, etc.

Em O Fantástico Circo-Teatro de um Homem Só, a referência do circo ofereceu o amálgama para os desejos de um espetáculo que incorporasse canções, jogos com o público, variação de personagens, números diversos desejos propulsores do ator, em diálogo com seu repertório a partir da inspiração na cultura popular brasileira. Na montagem, o palhaço, a mulher barbada, a vedete, entre outros tipos mais ou menos desenvolvidos, articulam-se com uma dimensão autobiográfica, compondo um circo singular em uma narrativa plural.

5 Desenvolvida na tese de doutorado La ética de la festividade en la creación escénica (Fagundes, 2010). 
Figura 1: O Fantástico Circo-Teatro de um Homem Só, Heinz Limaverde.

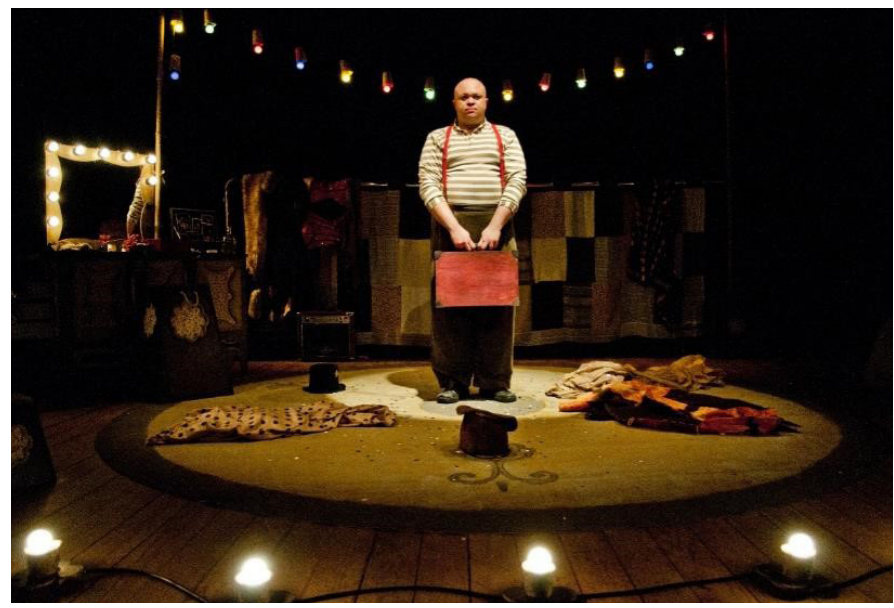

Foto: Kiran Federico Leon

Natalício Cavalo estrutura-se a partir da narrativa da vida e morte do personagem que dá nome à peça, em uma dramaturgia que envolve o trânsito entre narração e diálogo, atores e personagens, canções e vídeos, saltos e inversões no tempo, rupturas. Nesse caso, a linha da biografia, o fluxo da vida entre nascimento e morte do ser humano é a estrutura referencial, em uma dramaturgia episódica e não linear.

Boca no Mundo inspira-se no modelo de conferência ou aula, jogando com a própria experiência do ator, também professor universitário. A partir desse modelo, apropriam-se elementos, como a exposição didática, o quadro branco, fragmentos textuais teóricos, direcionamento direto ao espectador, desenvolvimento de temas históricos (como a imigração alemã no Rio Grande do Sul e a formação violenta do Brasil), para compor uma dramaturgia entremeada com material biográfico.
Figura 2: Boca no Mundo, $\mathrm{Na}$ imagem: Carlos Moedinger.

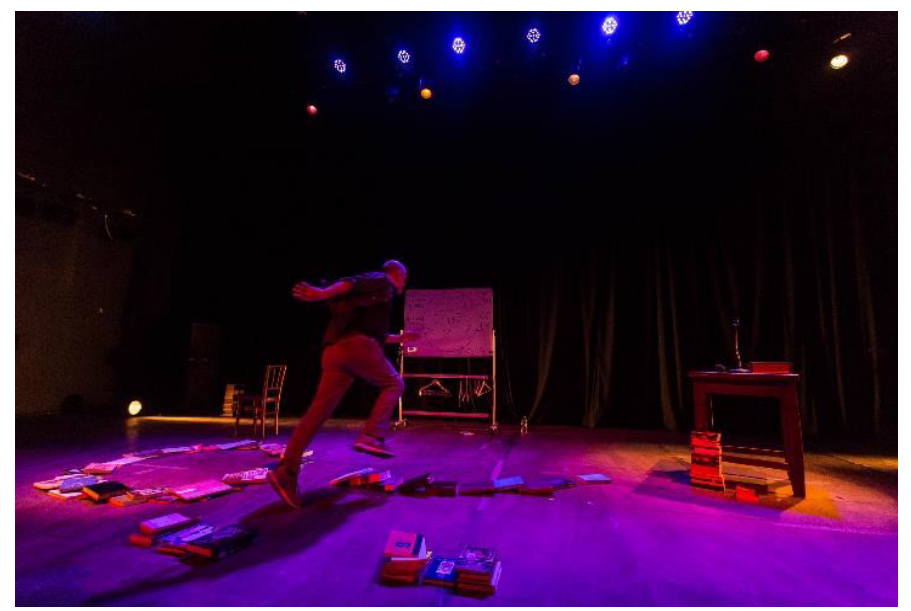

Foto: Adriana Marchiori

Temática: como a estrutura, o tema pode promover fluxos criativos sem definir formatos cênicos. Opera como um universo referencial, um território a explorar que ativa possibilidades e sugere movimentos. Ao definir-se um campo temático como ponto de partida em um processo criativo, ativam-se buscas, discussões, memórias, referências, nos artistas envolvidos. Podemos pesquisar colaborativamente fontes teóricas ou a Internet, realizar entrevistas com pessoas na rua, acessar documentos e realizar outros procedimentos, de acordo com o tema abordado. Os ensaios podem ser planejados em função de aspectos da temática: se partirmos do tema "fracasso", como em Clube do Fracasso, por exemplo, poderemos investigar corporalmente a queda, acessar memórias da infância, fazer listas de nossos maiores fracassos ou usar outros gatilhos de depoimento pessoal, improvisar situações de fracasso. O tema pode, ainda, sugerir diversas incorporações: fragmentos teóricos, notícias, depoimentos pessoais, imagens, situações, movimentos. Desenvolver a criação a partir de um tema, refletindo filosófica e politicamente sobre ele, não configura necessariamente um "ensaio cênico", como proposto por 
Lehmann (2006, p. 190-192), ainda que se relacione a essa possibilidade de "investigação cênica e teórica de ideias” (2006, p. 191).

Figura 3. Clube do Fracasso. Na imagem, Francisco de los Santos, Heinz Limaverde, Lisandro Belotto e Priscilla Colombi.

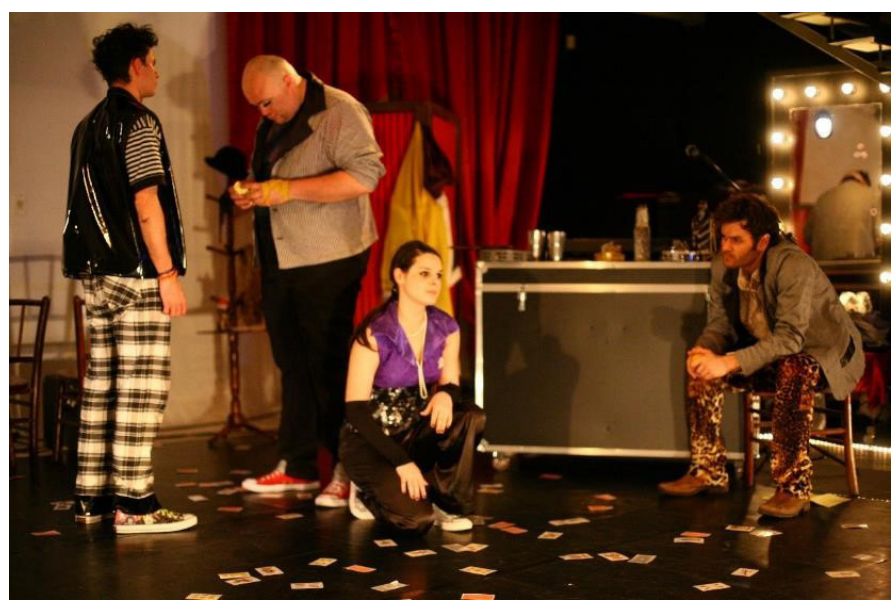

Foto: Alex Ramirez.

No espetáculo-intervenção Cidade Proibida, a temática da cidade, nosso habitar e convívio urbano, constituiu o propulsor básico para a criação, estruturando-se em cenas com focos diversos: textos sobre a cidade, desfile de tipos, canções, número com plateia conduzido por uma drag queen (o que você venderia/não venderia na sua cidade?), danças, manifesto.

A criação de Desmedida Naichty Club, dentro do frame de um show noturno, operou a partir da temática de desvios dos padrões hegemônicos normatizados, um elogio de diferentes desmedidas em uma sociedade que exclui diferenças e condena "excessos", ou transbordamentos de possibilidades fora da ordem - as cenas organizaram-se como desmedida do peso, da viadagem, do tempo, da raiva, etc.
Figura 4 : Desmedida Naichty Club, 2018, HeinLimaverde.

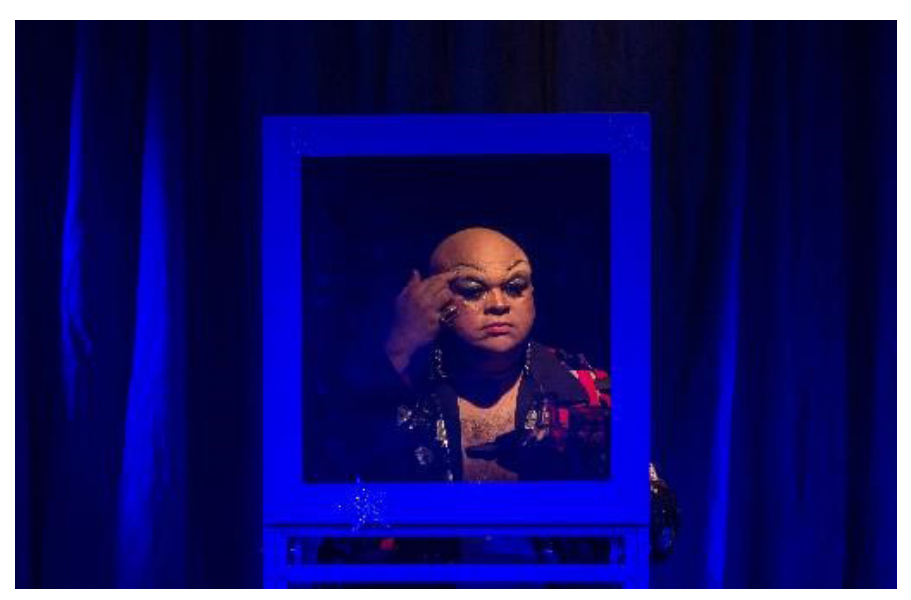

Foto: Adriana Marchiori.

Espaço e recursos concretos: a criação cênica pode ser compreendida como uma ação, um movimento em um espaço e tempo concretos, que são sempre definidos por processos de interações. Govan, Nicholson e Normington (2007) chamam a atenção para a diferença entre "lugar", uma localização geográfica definida por certa regulamentação, e "espaço", o produto de um conjunto de interações sociais, em constante transformação. Na ciência contemporânea (assim como em outras perspectivas distintas da noção da modernidade europeia), o conceito de tempo também dialoga com a ideia de fluxo de relações, o que remete a uma noção mais festiva do tempo, percebido como não linear, relativo, subjetivo, fora do cotidiano cronológico. Na cena, os vetores espaço-tempo são muitas vezes explorados como experiência física e sensorial, como matéria que nos informa e também que informamos: podemos moldar, dilatar, contrair, fragmentar, submergir, fundir, mesclar, contrapor, compor, inventar narrativas de tempo-espaço.

Se toda composição cênica propõe uma espacialização de corpos em certo tempo, a exploração de possibilidades narrativas a partir do tempo-espaço pode constituir uma importante plataforma de criação: em propostas 
articuladas como site-specific (criando a partir das características peculiares de um lugar, seja um bairro, um bar, um navio, um parque), na exploração de diretrizes de espacialização e corporeidade (um espetáculo criado a partir de possibilidades de queda e voo, por exemplo), com distintas configurações da disposição ator-espectador, com variadas durações, no uso lúdico de estruturas cenográficas incorporadas desde o início dos ensaios (oferecendo espécies de playgrounds para a composição: escadas, tonéis, andaimes, cadeiras, mesas, instrumentos musicais, figurinos), etc. Objetos podem ser geradores de espaço e dramaturgia; os próprios princípios de espacialização da encenação sugerem jogos de composição cênica e dramatúrgica.

Nas montagens citadas, princípios de disposição e composição espacial, assim como elementos cenográficos, constituíram elementos de composição desde o início dos ensaios: uma mesa, três cadeiras e um sofá-cama (em Fala do Silêncio), caixas de diversos tamanhos e painéis com rodas (Natalício Cavalo) ou livros, quadro branco, mesa e cadeira (Boca no Mundo).

Em Cidade Proibida, o espaço constituiu um recurso fundamental, primeiramente pela demanda de ser apresentado em parques, praças ou outros locais urbanos de possível convívio que se tornam proibidos durante a noite pela ameaça de violência, o que define uma relação tanto temática quanto contextual (o próprio convívio de pessoas no espaço é parte do conceito) e visual (o espaço aberto). Em segundo lugar, os recursos cenográficos, incorporados desde o início ao processo, definem possibilidades de ação e organização espacial fundamentais no jogo cênico - uma longa plataforma elevada, com rampas e escadas de acesso, sugere uma passarela, uma rua, uma passagem onde caminhadas, desfiles, coreografias, canções e manifestos se sucedem, evocando atmosferas e situações da urbanidade. Além da plataforma, tonéis e cones sinalizadores compõem os recursos espaciais.

Figura 5: Cidade Proibida em Pelotas, 2018. $\mathrm{Na}$ imagem: Ander Belotto, Camila Falcão, Di Nardi, Gabriela Chultz, Heinz Limaverde, Laura Backes, Lisandro Belotto, Mirna Spritzer, Priscilla Colom-

bi, Roberta Alfaya, Rodrigo Shalako, Suzi Weber.

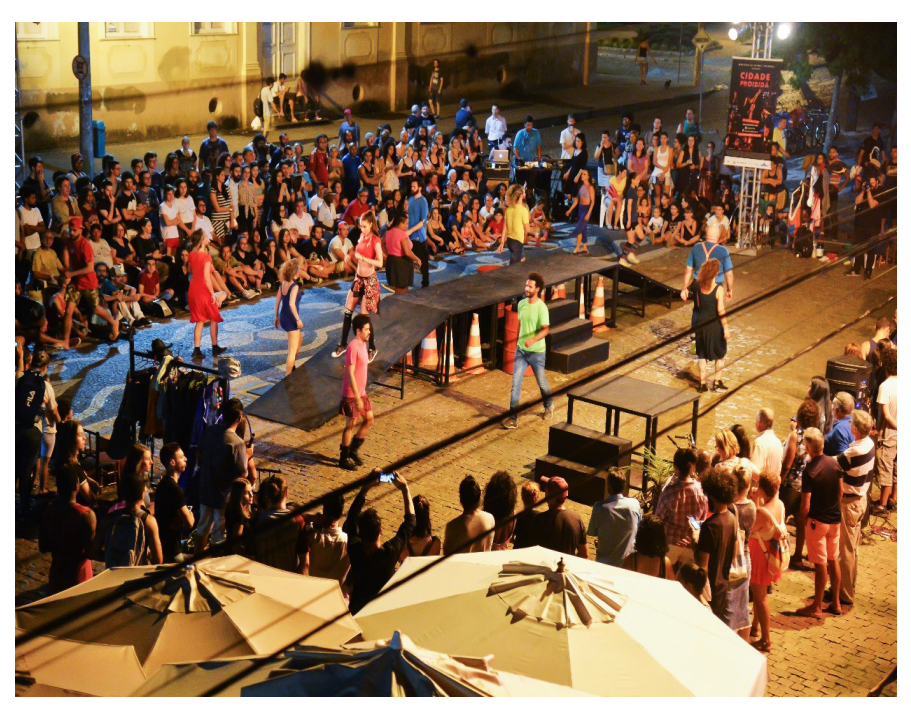

Foto: Janine Tomberg.

MATÉRIAS: estruturas e temáticas são desenvolvidas com materiais diversos, que dão carne e corpo ao mapa em processo; as estruturas alavancam o desenvolvimento das matérias e são simultaneamente preenchidas, modeladas, encarnadas por elas. Trataremos como possibilidade de matérias: biografias, recortes, documentos e repertório. Nada impede que diversas matérias sejam acionadas em uma mesma montagem, ou seja, a composição dramatúrgica de um espetáculo pode misturar material biográfico com recortes de um texto dramático, notícias de jornal e balé, seguindo os princípios de mistura, colagem e festividade criativa que a constituem.

Biografias: a incorporação de material biográfico enunciando-se como tal é procedimento artístico em destaque nas últimas décadas, que corresponde tanto à necessidade de articular outras narrativas quanto à 
própria fome de verdade em tempos de espetacularização da existência. A perspectiva biográfica e suas micro-histórias oferecem a possibilidade de verdades transitórias e localizadas, experiências específicas que podem ser associadas pelo espectador às suas próprias experiências, fugindo de narrativas absolutas. Podemos pensar que toda arte é autobiográfica em alguma medida, já que é articulada a partir das experiências de vida de quem cria. Tem cor, gênero, sexo, classe, trajetória....Nesse sentido, dialoga com a noção de "lugar de fala", que evidencia a condição social-individual de quem articula narrativas, desconstruindo a possibilidade de imparcialidade ou universalidade: "ao promover uma multiplicidade de vozes, o que se quer, acima de tudo, é quebrar com o discurso autorizado e único, que se pretende universal" (RIBEIRO, 2018, p. 70).

O formato de depoimento pessoal, por exemplo, costuma compor uma narrativa que corresponde ao corpo de quem enuncia, evocando a sensação de verdade e intimidade que a confissão, o compartilhar experiências, pode oferecer. É importante considerar que não se trata da importância de experiências privadas; ao trabalhar-se com as próprias memórias e perspectivas, ao oferecerem-se testemunhos, podem-se acionar as vivências de quem assiste, atualizando-se o vivido, nesse espaço virtual "entre" o palco e a plateia onde se dá o teatro. Assim, a experiência do eu constrói-se em relação ao outro, o sentido faz-se no "entre", onde o individual é também social.

$\mathrm{O}$ trabalho com material biográfico não define um estilo teatral determinado, como o formato da cena em primeira pessoa, tampouco é restrito aos arquivos dos próprios artistas. Pode partir das histórias de outras pessoas ou de comunidades e grupos específicos, e assumir múltiplos formatos narrativos, mais ou menos épicos, dialógicos, poéticos, etc. Materiais podem ser reunidos por meio de entrevistas, pesquisas em arquivos históricos e fontes teóricas, coleta de depoimentos, etc., materializando-se em cena como texto enunciado pelo elenco, inserção de vídeos, narração, situações dramatizadas. O trânsito entre o real e o ficcional é uma tensão sempre presente no universo da biografia, ainda que tais limites não possam ser definidos com precisão - a própria memória é feita também de imaginação.

Clube do Fracasso desenvolvia ambas as abordagens, compondo tanto com fragmentos biográficos da equipe envolvida (o elenco assumia seus próprios nomes na cena) quanto com depoimentos coletados em entrevistas na rua, que eram projetados no espetáculo como cenas próprias. Algumas confissões em primeira pessoa não correspondiam a quem enunciava o texto, jogando com a dimensão ficcional da narrativa pessoal e da própria memória.

Ainda que não sejam sempre enunciadas em primeira pessoa, todas as montagens consideradas aqui tratam com material biográfico, de diferentes modos - as matérias não constituem estilos.

Repertório: toda criação vale-se de certo repertório que nos constitui: tanto referências e técnicas do ofício, quanto experiências da vida e do mundo, como nossa cultura, redes, práticas, saberes; possíveis habilidades do artista, como canto, dança, bambolê, poesia, acrobacia, instrumentos musicais, luta, etc.; repertório de vida, como memória, vivências, viagens, estudos, desejos, referências. Além de compor todo ato criativo, o repertório pode encarnar partes da dramaturgia como matéria concreta, nessa perspectiva enviesada, corpórea e processual de dramaturgia. É um recurso especialmente importante em processos de ensaios compactos, organizados em períodos intensos e enxutos, como intervenções, manifestos, oficinas, cabarés - 
estratégias urgentes de criação para tempos velozes, como os Cabarés da Rústica, que abordam questões políticas da atualidade. Pode ser convocado diretamente, a partir de um inventariado das possibilidades dos artistas. Mesmo que material prévio seja incorporado, como, por exemplo, uma canção já trabalhada por uma atriz, a combinação específica de fragmentos diversos para a montagem em questão garante sua singularidade (a composição dramatúrgica trabalha com colagem, reinvenção e, inclusive, reciclagem, procedimentos de nosso tempo). Pode ser intencionalmente descoberto e ativado mediante jogos e práticas corporais e também a partir de perguntas diretamente relacionadas ao universo cênico investigado: o que cada um pode e deseja oferecer para nossa festa, nossa criação compartilhada?

De modo geral, as montagens consideradas tomam como ponto de partida recursos, possibilidades, desejos e interesses dos atores e atrizes envolvidos na criação, o que em alguns casos se acentua especialmente.

Figura 6: Cabaré do Amor Partido.

$\mathrm{Na}$ imagem, Roberta Alfaya, Lisandro Bellotto, Lucca Simas, Leonardo Machado e Suzi Weber.

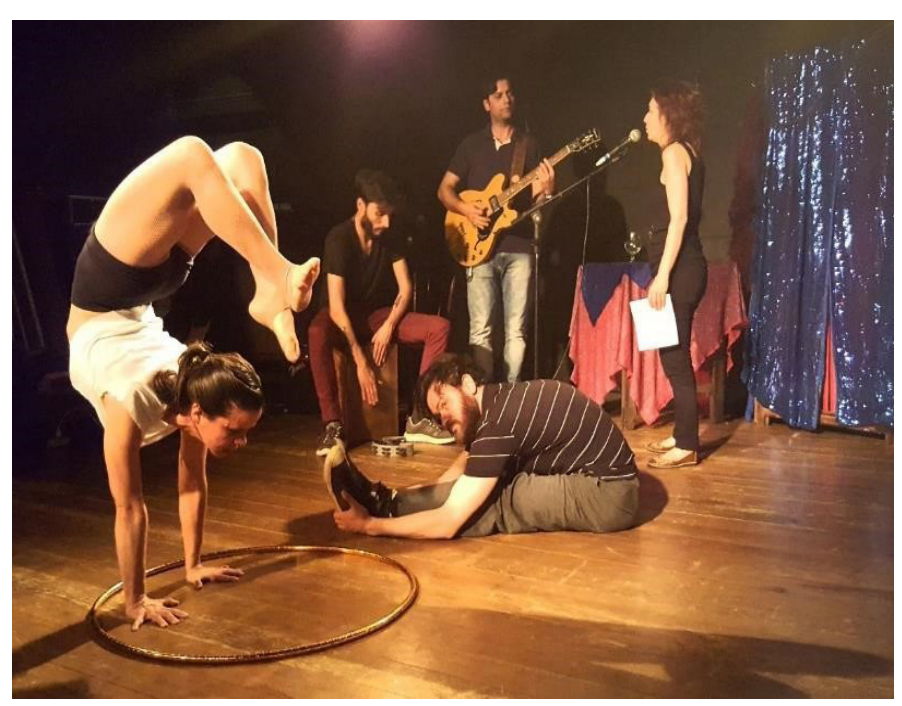

Foto: Patricia Fagundes
Documentos: fotografias, vídeos, cartas, anexação de testemunhos e relatos, mapas, canções, objetos: incorporação de documentos e fragmentos do mundo, que propõem jogos entre real e ficção ou inserem o real no corpo da ficção, neste provocar e borrar de fronteiras tão recorrente da arte contemporânea. Os documentos podem desvendar a narrativa que está sendo desenvolvida, que pode ou não estar no campo do ficcional, podem com ela colaborar ou propor contrapontos, outras camadas.

Em Natalício Cavalo, certos episódios da vida do personagem central contavam com projeções de reportagens, cartas e fotografias, documentos reais, tecidas com a composição cênica. O borramento de fronteiras entre real e ficção, questão tão cara na arte contemporânea, era uma intenção da montagem. O título já propunha um nome inventado para uma pessoa real: Natalício Cavalo é Valter Fagundes, pai da diretora do espetáculo. Porém, nas reportagens (de rodeios que ele havia organizado no interior do Rio Grande do Sul) e nas cartas (enviadas por ouvintes do programa de rádio em que era locutor), os nomes reais foram alterados.

Figuras 7 e 8. Natalício Cavalo. No elenco, Rossendo Rodrigues, Priscilla Colombi, Marcelo Mertins, Lisandro Bellotto, Heinz Limaverde e Marina Mendo.

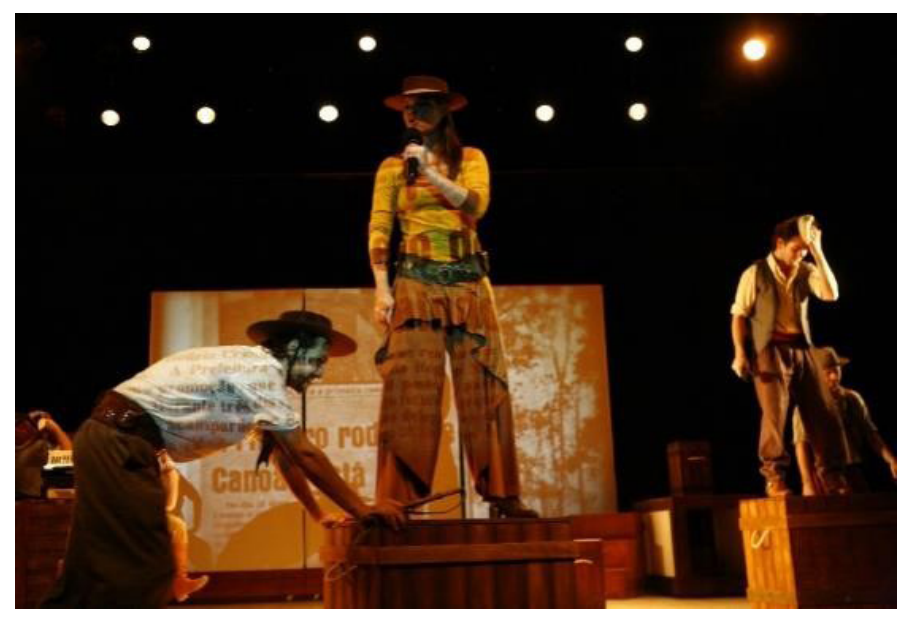




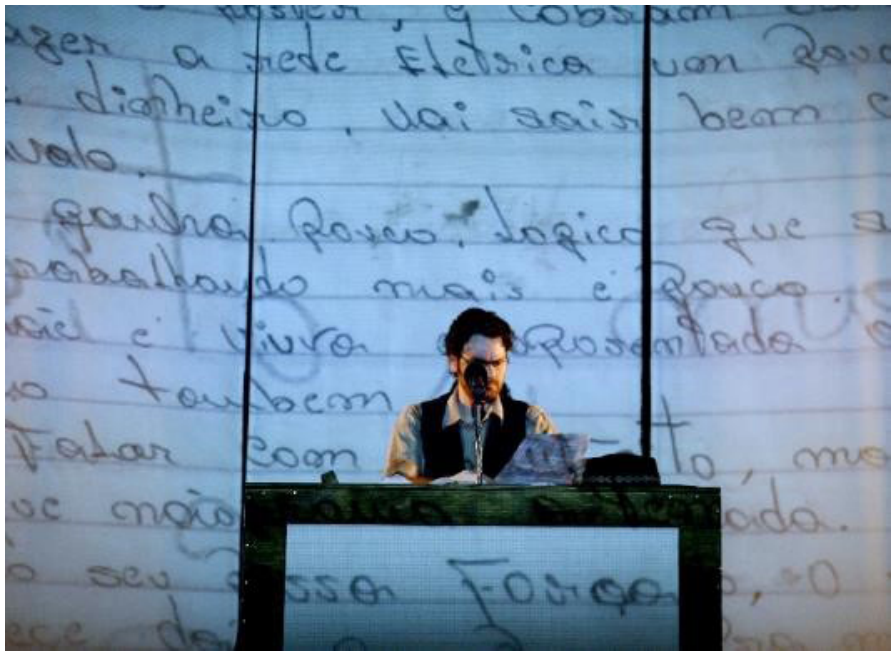

Foto Alex Ramirez.

Em Fala do Silêncio (livre adaptação-reinvenção de Betrayal, de Harold Pinter, atualizada para o Brasil de 2016 a 2007 -a narrativa estrutura-se em ordem cronológica inversa), inseriam-se projeções de imagens de telejornais, manifestações e flashes de acontecimentos políticos entre as cenas da narrativa, centrada em um triângulo amoroso. A ideia era compor uma fricção entre vida privada e realidade social, evidenciar tensões entre espaços íntimos e tensões históricas que invadem a sala de jantar.

Figura 9 e 10: Fala do Silêncio. Lisandro Belloto, Priscilla Colombi e Leonardo Machado.

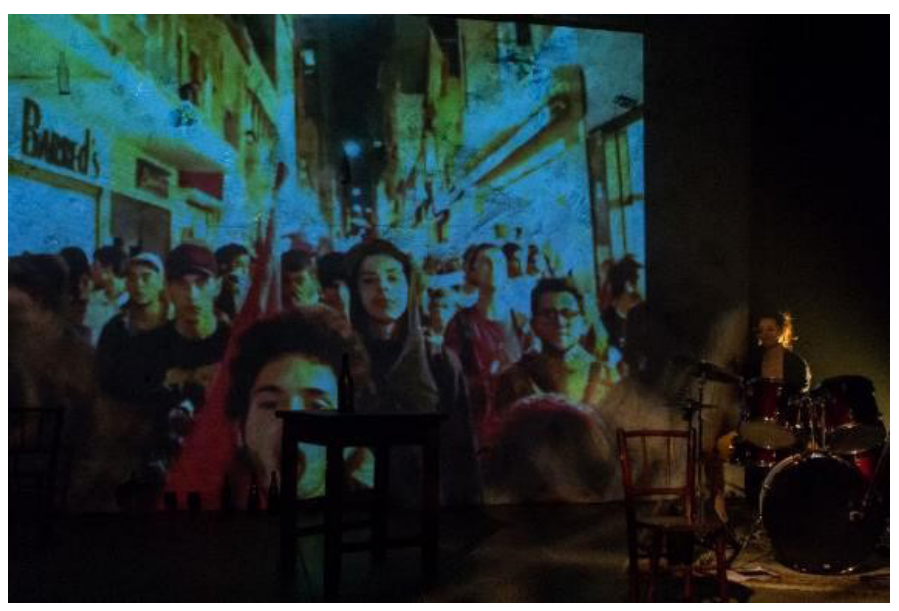

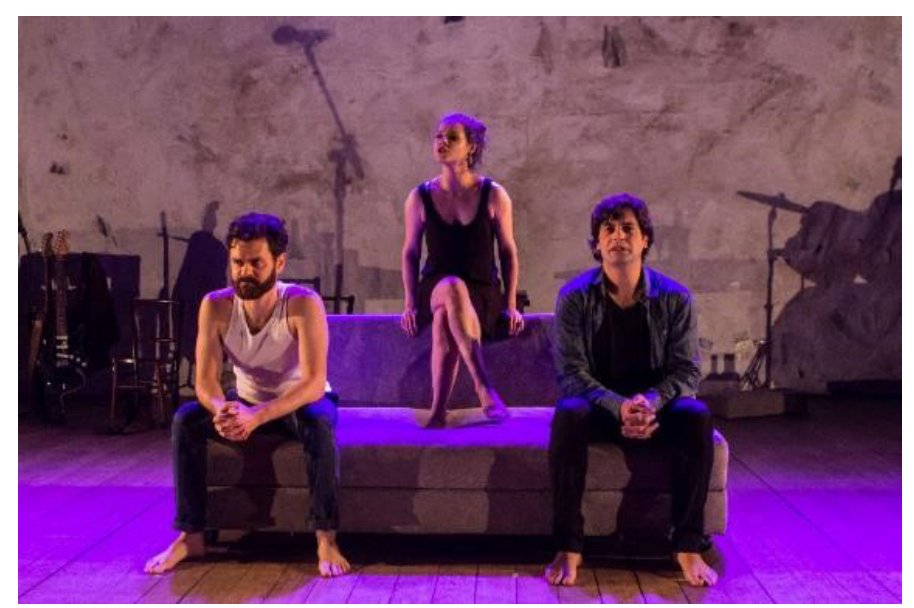

Foto: Adriana Marchiori.

Recortes: são semelhantes aos documentos, mas específicos em relação a materiais textuais anexados, misturados, absorvidos no corpo da dramaturgia, por meio de fragmentos de outros textos já existentes: canções, textos teóricos, sites de autoajuda, poesias, receitas de bolo, trechos de textos dramáticos, jogo com personagens existentes na literatura, etc.

DISPARADORES: escrita suada, perguntas, pesquisa, esporos. Os disparadores referem-se a possíveis procedimentos para gerar e desenvolver matérias e articular plataformas, ou seja, exercícios de ensaio, práticas cênicas.

No campo de experiência deste trabalho, essas práticas são frequentemente desenvolvidas como uma "escrita suada": exercícios de escrever são propostos para o elenco imediatamente após a realização de atividades/vivências corporais mobilizadoras. Escrever com o corpo, entendendo corpo como o que somos; o teatro, como uma prática corpórea; a própria escrita, como prática criativa que acessa outras possibilidades mediante estados corporais diferenciados.

Após dinâmicas corporais diversas, relacionadas ao universo a ser desenvolvido, papel e caneta são distribuídos; os artistas, espalhados pelo espaço, são provocados a escrever individualmente. A escrita suada é 
acionada a partir de questões objetivas, relacionadas de alguma forma às buscas temáticas de cada processo e à prática corporal proposta, como, por exemplo: "o que é um coração partido", "lista de teus dez maiores fracassos", "quando quis fugir com o circo", "carta para alguém importante do passado", "o que a cidade é e o que a cidade não é", "lista do que mais gostava de fazer quando criança", "o que é importante lembrar e esquecer", etc.

Improvisações diversas com motivações específicas que investiguem cenicamente 0 universo a ser desenvolvido são outro recurso importante. Um exemplo de exercício improvisacional disparador de material textual são as "frases gatilho em looping", que, inclusive, podem definir diretamente parte da dramaturgia textual. Movimentando-se pelo espaço de acordo com diferentes indicações, as pessoas enunciam e completam frases predefinidas, como, por exemplo: "o que eu mais gosto é...", "o que eu mais odeio é...", "meu primeiro amor foi...".

Outro motivador de improvisação, no campo de experiências criativas considerado, são os esporos ${ }^{6}$, que se constituem como fragmentos de cenas, em forma de diálogos, episódios ou narrações, no caso propostos pela encenadora/compositora para desenvolver em ensaio. Muitas estratégias podem ser utilizadas em sua "germinação": improvisações, workshops, composições sonoras, composições visuais.

A pesquisa externa, fora da sala de ensaio, também é um procedimento fundamental. Além da investigação própria de qualquer processo criativo, que acontece com os artistas envolvidos até mesmo involuntariamente no cotidiano, propõem-se questões e tarefas: coleta de frases ouvidas

6 Esporos, na área da Biologia, define unidades de reprodução; formas latentes de muitos animais ou seus embriões, uma célula envolvida por uma parede celular que a protege, até as condições ambientais se mostrarem favoráveis à sua germinação. na rua, pesquisa de poemas ou canções relacionadas, coleta de referências, escritas de textos. Esse material é compartilhado entre todos, formando um arquivo comum da montagem, que pode gerar texto e cena.

\section{MONTAGEM}

a montagem é um procedimento fundamental na composição dramatúrgica, tecida continuamente junto com a encenação e a atuação. Durante todo o processo, o material produzido é selecionado, editado, organizado na estrutura desejada, compondo com a diversidade de fontes e autorias, formatos e pontos de vista, gerados ou coletados durante o processo: memórias pessoais, movimentos, jogos, espaço, notícias, textos existentes, material da Internet, canções, fatos históricos, etc. Esses materiais são apropriados e reinventados em procedimentos de justaposição, colagem, mixagem, adaptação. Uma colcha de retalhos plural, que recicla possibilidades - reciclar, aproveitar o existente, mobilizando arquivos da cultura e a arte, não seria uma perspectiva fundamental de nosso tempo?

São procedimentos que se aproximam também da perspectiva de bricolagem, noção que em si já é uma constelação de apropriações, que passam por Lévi-Strauss, Derrida, Certeau, pesquisa educacional (NEIRA; LIPPI, 2012) e pelo próprio fazer artesanal que deu origem à palavra: pensamentos e fazeres que compõem a partir de materiais já existentes, incorporando diferenças, trabalhando a partir da experiência. Um saber/fazer sensível que faz uso de diferentes estratégias e materiais, colando fragmentos de diversas fontes, entretecendo múltiplas perspectivas:

Entretecer significa vamos tecer juntos, tecer entremeando. (...)Tecer juntos, entremeando, almeja uma produção coletiva de conhecimentos, respeitadora de múltiplas perspectivas e que contemple 
o ir e vir, o relativo, o temporário e o imprevisível da complexidade contemporânea. (NEIRA; LIPPI, 2012, p. 612).

É importante frisar que a montagem não é realizada depois de definir ou concluir plataformas, matérias e disparadores; a composição dramatúrgica funciona em ciclos de retroalimentação contínuos. Vai sendo experimentada, saboreada, inventada como um dos procedimentos do processo de criação.

Compartilhar modos de um fazer dramatúrgico implica compartilhar modos de pensar, articular, tecer, agir na cena e no mundo. Se o fazer cênico habita o "entre" e é composto de rede de relações, a ética apresenta-se como um elemento definidor de seus processos. O sociólogo francês Michel Maffesoli (2007) identifica a emergência de uma "ética da estética" no contexto contemporâneo, definindo a estética como a faculdade de experimentar em comum, e a ética, como o que permite a união de uma comunidade, espécie de "argamassa" social. A relação entre ética e estética se estabelece por meio da experiência compartilhada, corpórea e sensível, em um espaço onde ética e estética operam como vetores indissociáveis - assumimos a noção de est(é)tica para pensar dinâmicas de criação cênica que inventam microterritórios sociais efêmeros onde outras realidades são possíveis.

Constituindo-se como prática de criação cênica, atravessada por questões est(é)ticas e políticas, a composição dramatúrgica assume como recursos fundamentais as dinâmicas relacionais presentes nos processos de ensaios e o universo de experiências e possibilidades dos próprios artistas envolvidos, ambos marcados pelo contexto histórico-social em que vivemos. Desde o sul do sul, talvez sejamos nós mesmos nosso mais importante capital artístico. Nossos corpos, memórias, ideias, desejos, palavras, movimentos, nosso amor e nossa fúria. Nossas histórias, quem somos, quem fomos e quem podemos ser. Sem idealizar práticas de colaboração, território pleno de conflitos e fricções, o ato de compartilhar é um caminho possível frente aos desafios e precariedades que enfrentamos. Compor implica reconhecer e reinventar as narrativas que fazemos e que nos fazem, em uma prática impregnada de suor, alteridade e amor - amor entendido como capacidade de escuta do outro (SPRITZER, 2010) ou fundamento biológico do social (MATURANA; VARELA, 2009). O teatro oferece um espaço para contar as histórias que necessitamos contar, dos modos enviesados e festivos que podemos inventar a cada processo, compondo com o outro, entretecendo com o mundo e com o tempo.

\section{Referências}

CANTON, Katia. Temas da Arte Contemporânea (coleção). São Paulo: Martins Fontes, 2009.

CAUQUELIN, Anne. Teorias da Arte. São Paulo: Martins Fontes, 2005.

FAGUNDES, Patricia. La Ética de la Festividad en la Creación Escénica. Madrid: Universidad Carlos III de Madrid, 2010. TeseUniversidad Carlos III de Madrid, Doutorado em Humanidades - Ciencias del Espectáculo.

GOVAN, Emma; NICHOLSON, Helen; NORMINGTON, Kate. Making a Performance: Devising Histories and Contemporary Practices. London and New York: Routledge, 2007.

LEHMANN, Hans-Thies. (1999) Teatro Pós-Dramático. São Paulo: Cosac Naify, 2007. 
LIMA, Eugenio. Descolonizar o teatro por todos os meios necessários. Entrevista concedida a Andrei Reina. Bravo!, ano 3, dez. 2017. Disponível em: <<https://medium.com/revista-bravo/descolonizar-o-teatro-por-todos-os-meios necess $\% \mathrm{C} 3 \% \mathrm{~A} 1$ rios-45a6994563f4. >>. Acesso em: 17 set. 2018.

MAFFESOLI, Michel. En el crisol de las apariencias. Para una ética de la estética. Madrid: Siglo XXI, 2007.

MATURANA, Humberto; VARELA, Francisco. El Árbol del Conocimiento: Las bases biológicas del conocimiento humano. Madrid: Debate, 1999.

NEIRA, Marcos Garcia; LIPP, Bruno Gonçalves. Tecendo a Colcha de Retalhos: a bricolagem como alternativa para a pesquisa educacional. Educação e Realidade, Porto Alegre, v. 37, n. 2, p. 607-625, maio/ago. 2012.

NOVARINA, Valere. Diante da Palavra. Rio de Janeiro: 7Letras, 2009. RIBEIRO, Djamila. O que é lugar de fala? Belo Horizonte: Letramento: 2017.

SPRITZER, Mirna. Ator e palavra: práticas da vocalidade. Abrace: 2010.

Recebido: 17/06/2019

Aprovado: 20/11/2019 